\title{
The Contribution of Informal Logic to Public Health
}

Professor Louise Cummings D.Phil, School of Arts and Humanities, Nottingham Trent University, Clifton Lane, Nottingham, NG11 8NS.

Email: louise.cummings@ntu.ac.uk; Tel: (0115) 8483138

Public health has always been open to research in a wide range of disciplines. These disciplines include fields within the physical and natural sciences, but also social scientific and humanities subjects. One humanities subject in particular has greater relevance than most to public health. That subject is philosophy. Beyond the obvious contribution of philosophy to public health in areas like ethics, philosophy can contribute insights on issues such as the nature of knowledge and reasoning. In fact, such is the reach of philosophy into public health that Christakos et al. ${ }^{1(p 66)}$ have remarked that '[i]n the end, public health scientists may find themselves acting as a kind of applied philosopher. The interdisciplinary, multi-cultural, and multi-objective nature of the world could leave them no choice.' (italics in original) In this article, I want to argue that a philosophical discipline known as informal logic has an important contribution to make to public health.

Informal logic is a relatively recent development in the long history of logic. It is concerned with the study of argument forms that are not amenable to analysis within formal (deductive) logic. The impetus for a separate discipline of logic arose when it became apparent that although people are capable of engaging in deductive reasoning, they are much more likely to use plausible or presumptive reasoning in their everyday affairs. ${ }^{2}$ The hallmark of this type of reasoning is that it is sensitive to features of context. As such, it is defeasible in a way that deductive reasoning is not (features of context, after all, are not 
immutable but are subject to change). This new emphasis on examining arguments in the contexts in which they occur had important implications for one group of arguments in particular, known as the informal fallacies. These arguments, which include such names as the argument from ignorance and question-begging argument, had traditionally been characterized as weak or fallacious forms of reasoning. However, when examined in the contexts in which they are advanced, it became increasingly apparent to logicians that these arguments have certain merits. ${ }^{3-4} \mathrm{I}$ have argued that these merits include a capacity to bridge gaps in our knowledge of the type frequently encountered at the outset of a scientific inquiry. ${ }^{5-7}$ This lack of knowledge or uncertainty threatens to stall scientific inquiry which, in the case of public health, could delay the implementation of important protective health measures. In serving to bridge these gaps in knowledge, the informal fallacies can be seen to confer epistemic gains on scientific inquiry.

In Cummings, ${ }^{8}$ I used concepts and techniques from informal logic to conduct an analysis of the reasoning of scientists who were called upon to consider the public health risks posed by the emergence of BSE in British cattle. That study revealed that argument forms such as the argument from ignorance and question-begging argument were commonly found in the reasoning of scientists who sat on expert scientific committees such as the Southwood Working Party. Although the details of that analysis are beyond the scope of this article, a brief examination of one of these argument forms - the argument from ignorance demonstrates the type of factors that played a role in that analysis. In any argument from ignorance, one argues from a lack of knowledge (evidence or proof) that $X$ is true to the conclusion that $X$ is false (alternatively, from a lack of knowledge that $X$ is false to the 
conclusion that $X$ is true). In schematic form, this argument appears as follows, where $X$ may be taken to stand for a proposition, statement or claim:

There is no evidence that $X$ is true (premise) Therefore, $X$ is false (conclusion)

'No evidence' arguments of the above type were used so extensively by scientists during the BSE epidemic that Lord Phillips ${ }^{9}$ called them the 'mantra' of the BSE affair. One such argument is presented below:

There is no evidence that scrapie is transmissible to humans (premise)

Therefore, scrapie is not transmissible to humans (conclusion)

The argument from ignorance is a rationally warranted form of argument when two conditions are satisfied: (1) the knowledge base in a particular domain is complete or closed and (2) the knowledge base has been exhaustively searched. In the case of the above argument, both these conditions were fulfilled. Extensive epidemiological investigations of scrapie and CJD had been conducted over many years and in different countries (i.e. the epidemiological knowledge base was complete). Also, a review ${ }^{10}$ of these investigations failed to find any evidence of a link between scrapie, a TSE of sheep, and human disease (i.e. the epidemiological knowledge base had been exhaustively searched). Under these conditions, it was rational for scientists to conclude that scrapie is not transmissible to humans. The use of an argument from ignorance by scientists had effectively transformed a negative epistemic situation (a lack of knowledge of the transmissibility of scrapie to 
humans) into a positive epistemic situation (a claim to the effect that scrapie is not transmissible to humans). This transformation had certain benefits for scientists. Chief among them was that the conclusion of this ignorance argument - scrapie is not transmissible to humans - could be employed as a premise in further reasoning that was used in making risk assessments and in instituting health protective measures. This is exactly what happened during the BSE epidemic, with scientists using the conclusion of this ignorance argument to warrant decisions such as the measures to take in order to contain BSE (e.g. the tissues to include in the Specified Bovine Offal ban).

The reasoning strategies discussed above are not confined to the specific public health problem posed by BSE. They have also been analysed in relation to HIV/AIDS. ${ }^{11}$ In fact, their presence is so widespread in public health reasoning that I believe it is important for public health researchers and practitioners to be cognizant of this group of arguments. Certainly, these arguments represent an important rational resource which could be usefully exploited in the public health field.

\section{References}

1. Christakos G, Olea RA, Serre ML, Yu H-L, Wang L-L. Interdisciplinary Public Health Reasoning and Epidemic Modelling: The Case of Black Death. The Netherlands: Springer; 2005.

2. Walton DN. Argumentation Schemes for Presumptive Reasoning. Mahwah, NJ: Lawrence Erlbaum Associates; 1996. 
3. Woods J. The Death of Argument: Fallacies in Agent-Based Reasoning. Dordrecht: Kluwer Academic Publishers; 2004.

4. Walton DN. Informal Logic: A Pragmatic Approach. 2nd ed. Cambridge: Cambridge University Press; 2008.

5. Cummings L. Reasoning under uncertainty: The role of two informal fallacies in an emerging scientific inquiry. Informal Logic 2002;22(2): 113-136.

6. Cummings L. Emerging infectious diseases: Coping with uncertainty. Argumentation $2009 ; 23(2): 171-188$.

7. Cummings L. Considering risk assessment up close: The case of bovine spongiform encephalopathy. Health, Risk \& Society 2011;13(3): 255-275.

8. Cummings L. Rethinking the BSE Crisis: A Study of Scientific Reasoning under Uncertainty. Dordrecht: Springer; 2010.

9. BSE Inquiry. BSE Inquiry Report, Volumes 1 to 16. London: The Stationery Office; 2000.

10. Brown P, Cathala F, Raubertas RF, Gajdusek DC, Castaigne P. The epidemiology of Creutzfeldt-Jakob disease: Conclusion of a 15-year investigation in France and review of the world literature. Neurology 1987;37(6): 895-904.

11. Cummings L. Analogical reasoning as a tool of epidemiological investigation. Argumentation 2004;18(4): 427-444. 